THE INTERNATIONAL

REVIEW OF RESEARCH IN

OPEN AND DISTANCE LEARNING

\title{
Online Social Networks as Formal Learning Environments: Learner Experiences and Activities
}

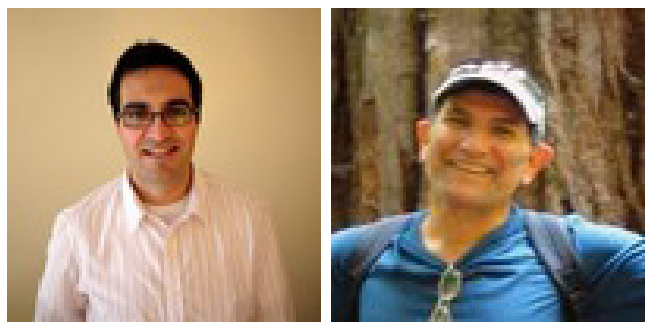

George Veletsianos and Cesar C. Navarrete University of Texas at Austin, USA

\section{Abstract}

While the potential of social networking sites to contribute to educational endeavors is highlighted by researchers and practitioners alike, empirical evidence on the use of such sites for formal online learning is scant. To fill this gap in the literature, we present a case study of learners' perspectives and experiences in an online course taught using the Elgg online social network. Findings from this study indicate that learners enjoyed and appreciated both the social learning experience afforded by the online social network and supported one another in their learning, enhancing their own and other students' experiences. Conversely, results also indicate that students limited their participation to course-related and graded activities, exhibiting little use of social networking and sharing. Additionally, learners needed support in managing the expanded amount of information available to them and devised strategies and "workarounds" to manage their time and participation.

Keywords: Online learning; learner experience; online learning environments; online social networks; social networking sites; Elgg

\section{Introduction}

Social networking sites (SNSs) have the potential to facilitate interaction, communication, and collaboration, and as a result have been prominently featured in discussions centering on the use of technology to support and amplify educational endeavors (Greenhow, Robelia, \& Hughes, 2009; Veletsianos, in press). Empirical research on their role in online education is limited, even though researchers have identified an accelerating use of social software in formal learning contexts (Schroeder, Minocha, \& Schneider, 2010). To fill this gap in the literature, we present a case study of learners' perspectives and experiences in an online course taught via an SNS. We studied SNS deployment and learner experiences in an ecological setting in order to capture both the implications of SNS use and the tensions 
that arose with the use of social networking sites in online education.

Historically, distance education (DE) has been plagued by feelings of learner isolation and alienation (Galusha, 1997), lack of participant interaction (both student-student and student-instructor), and high dropout rates (Peters, 1992). The rise of Web 2.0, social networking sites, and a general interest in student-centered pedagogies have attracted attention to the use of popular Internet tools to enhance distance education and address the aforementioned problems. For instance, Lee and McLoughlin (2010) suggest that online social networks enable learners and instructors to present themselves socially in an online environment and connect with one another while enabling individuals to engage in recurring meaningful experiences with others (Jenkins, Clinton, Purushotma, Robinson, \& Weigel, 2006; Wheeler, Yeomans, \& Wheeler, 2008). Nevertheless, prior research strongly suggests that technological innovations need to be accompanied by pedagogical enhancements for technology-rich interventions to be successful (Doering \& Veletsianos, 2008; Mishra \& Koehler, 2006; Hughes, Thomas, \& Scharber, 2006; Veletsianos, 2010). Researchers also recommend examining which course delivery format fits particular pedagogical approaches (Tallent-Runnels et al., 2006). Therefore, we purposefully chose to study a case in which a social networking site used in an online course was also accompanied by a socioconstructive pedagogical ethos. Our intention is not to examine the pedagogy independent of the technology, or vise versa. Rather, our objective is to describe and evaluate learner experiences to clarify what online education mediated by a social networking site used in conjunction with an SNS-oriented pedagogy might afford. To do so, we first present a review of the use of online social networks in higher education. Next, we present our research questions, study context, and methodology. We then discuss our findings and implications.

\section{Review of Relevant Literature}

Learners have turned to online distance learning as a reliable alternative to face-to-face education (Brady, Holcomb, \& Smith, 2010; DeSchryver, Mishra, Koehleer, \& Francis, 2009). One in four higher education students in the United States now take at least one online course during their undergraduate career (Allen \& Seaman, 2010). Distance education offerings have traditionally been organized and supported through learning management systems (LMSs) or content management systems (CMSs), such as Blackboard and Moodle, because these systems offer opportunities for organization, efficiency, and security (DeSchryver et al., 2009; Lee \& McLoughlin, 2010; West, Waddoups, \& Graham, 2006). Nevertheless, researchers have argued that these platforms have generally been used as static repositories of content, failing to provide the robust social experience found on platforms that have garnered societal interest and appeal, such as Facebook or YouTube (Brady et al., 2010; Lee \& McLoughlin, 2010; Schroeder et al., 2010; Whitworth \& Benson, 2010). Furthermore, learning and content management systems have been criticized for suppressing motivation and enthusiasm and failing to support personalization (DeSchryver et al., 2009; Naveh, Tubin, \& Pliskin, 2010), while also inhibiting broader pedagogical support with their default settings and familiar features (Lane, 2009). 
As a result, educators have begun exploring alternative platforms to provide learners with the social communication tools that allow for ease of use, pedagogical freedom, fluid online discussions, and identity management (Brady et al., 2010; Lee \& McLoughlin, 2010; Webb, 2009). Though institutions may not support a number of these platforms, popular Web 2.0 and social media tools have been appropriated in higher education, presumably because of their perceived opportunities and benefits. For example, instructors have asked students to maintain blogs and wikis hosted outside of the institution (e.g., on Wordpress.com) or have used an amalgamation of Web 2.o tools to develop unique online learning environments for their students (Conole, 2010). Online social networks have also been used in this context, and in a study conducted at a large university in the southeastern US, Ajjan and Hartshorne (2008) found that $56 \%$ of faculty believed such tools would be useful for student-to-student interaction.

The use of online social networks in educational endeavors has been supported by numerous educational technology researchers, who have highlighted the benefits of participatory technologies in formal learning contexts in K-12 (Barbour \& Plough, 2009; Greenhow et al., 2009) and higher education settings (DeSchryver et al., 2009; Veletsianos, 2011; Webb, 2009). Social networking technologies have been viewed as tools that enable the use of participatory pedagogies able to address the problems that have traditionally plagued distance education: creating a sense of presence, community-building, and learner participation in interactive discussions (Brady et al., 2010; Lee \& McLoughlin, 2010; Naveh et al., 2010). The literature suggests that using online social networks as educational platforms may support learners in forming social connections with others while they collaborate to share ideas, create products, construct identities, and receive timely feedback (Dron \& Anderson, 2009a; Greenhow, 2011; Wheeler et al., 2008). Additionally, research on informal learning within SNS contexts suggests that SNS participation fulfills important social learning functions (Greenhow \& Robelia, 2009), though Selwyn (2009, p. 170) argues the kind of learning that occurred in a study of naturally occurring Facebook interactions among undergraduates represents the "chatter of the back row of the lecture hall." On the other hand, Schroeder et al. (2010) offer a long list of potential issues that may arise when using social software in higher education. These include workload concerns for faculty and students, lack of trust in peer feedback, ownership issues with regards to public and collaborative spaces, difficulty in adapting publicly available tools, and difficulty in protecting the anonymity of students. Furthermore, Madge, Meek, Wellens, and Hooley (2009) have suggested that SNSs might be more useful for informal rather than formal learning as $91 \%$ of the undergraduates in their study never used such tools to communicate with university staff, and $43 \%$ believed that SNSs have no potential for academic work.

Indeed, there is a lack of literature examining social networking sites in higher education settings (Brady et al., 2010), and even less of that literature is focused on student experiences in online courses. The few studies that do exist, however, provide much-needed insight on the topic. Brady et al. studied one online and two hybrid graduate courses that used the Ning social network (http://www.ning.com/). After surveying the students, these researchers found that the majority of participants agreed that communication and collaboration 
were appreciably enhanced after using Ning. Results suggest that there are potential learning benefits derived from the SNS, leading these researchers to argue that the tool can potentially be used to improve learning experiences. Similar findings were reported by Wang, Woo, Quek, Yang, and Liu (in press), where the researchers found that students in two teacher education hybrid courses were satisfied with the use of the Facebook Group as an LMS, though features that were perceived to be of value to education (e.g., threaded discussions) were missing from this platform. Arnold and Paulus (2010) also integrated Ning into a blended course. In their case, Ning was used as a space to host blogs, discussion forums, and course information. Students in this study believed that social networking features of the site encouraged community-building, and the public nature of the tasks allowed for modeling and feedback. Nevertheless, student activity was generally limited to assigned tasks, even though the authors argue that further student activity might have taken place that was "invisible" to them. The authors argue that such activity (e.g., reading other students' entries but not responding) is important, and though sometimes pejoratively described as "lurking," may be a vital form of participation. Focusing specifically on online education, Dron and Anderson (2009b) studied an online undergraduate course taught via the Elgg social networking platform (which is the same platform used in this study). While their findings reveal that the learner experience was generally positive, these researchers also discovered that students were "lost in social space" and needed support and scaffolding to participate in the social network.

Our review of the literature suggests that SNSs hold promise for online education. Nevertheless, considerable gaps exist in the empirical literature, especially with regards to what the student experience is like in these environments. A contributing factor to these gaps is the scarcity of studies reporting on the use of social networks in formal education, with Arnold and Paulus (2010), Brady et al. (2010), Dron and Anderson (2009b), and Wang et al. (in press) being the exceptions at the time of writing.

\section{Research Questions}

Our goal is to identify, describe, and understand learners' experiences in an online course facilitated through a social networking platform. In particular, we pose the following research questions:

- What are student experiences in an online course taught on a social networking platform?

- How did students perceive the use of a social networking platform as the mechanism through which the online course was taught? 


\section{Study Context}

\section{The Course}

This study was conducted in the context of an optional online graduate-level course taught at a large public university in the United States. The course was part of an educational technology program, and the syllabus described the course as being focused on online education. One of the authors was the instructor of the course, and this was the first time that this specific course was offered online. The instructor had prior experience teaching online courses, often experiments with emerging technologies in his instruction, and was excited about the possibility of students having access to SNS-like functionality within a centralized space. The course ran during a six-week summer session and was composed of four weeks of instruction, one week in which students were asked to reflect on course content, and one week in which they spent their time writing a final paper.

The course had a consistent structure throughout the week. The instructor introduced a new topic every other day. On day 1, students were asked to read papers or watch/listen to resources shared by the instructor, respond to one or two self-reflective questions on their blogs, and locate and share a Web site pertinent to the readings. The last activity is referred to as the "social bookmarking activity" in the rest of this paper. On day 2, students were required to read their colleagues' reflections, post two questions/comments to two learners' blogs, and respond to all questions/comments left on their own blogs. This process continued for six days per week, and students were graded on all of these activities. The course included two additional activities: one was a critique of a research paper and the second asked participants to argue for or against a particular thesis in a debate in lieu of responding to self-reflective questions. The goal of this process was to initiate investigation of the content, while creating space for learner-centered exploration and discussion. Instructor activities to shape participation and motivate engagement included frequent commenting on student blog entries, occasional alerts directing students to particularly noteworthy comments from their colleagues, and an ethos of openness throughout the course encouraging students to suggest ways to improve it. For example, the debate activity described above was not in the original design of the course, but came about as a result of student suggestions.

\section{Elgg: The SNS Platform}

The course was taught via an Elgg environment hosted by the educational institution and closed to individuals not affiliated with the course. Elgg (http://elgg.org/) is an open source framework that enables designers to implement a variety of Web 2.0 tools such as blogs, social bookmarks, collaborative document authoring, and microblogging in a central space (Figure 1). 


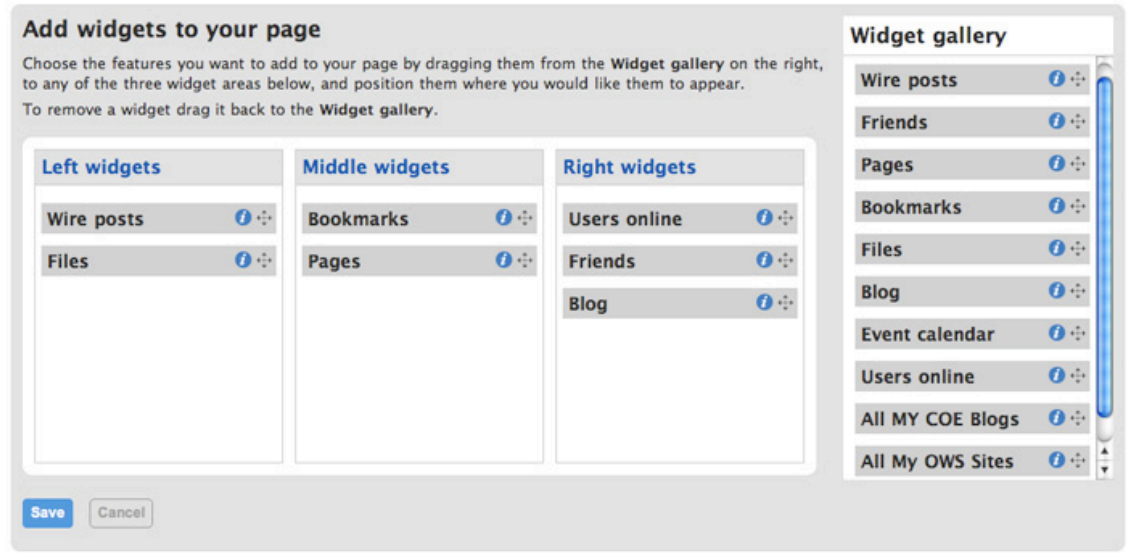

Figure 1. A selection of features available in Elgg.

Social networking functions are central to Elgg's design: students are able to create personal profiles and "friend" lists, post status updates, follow activity streams, and subscribe to be notified of other users' actions within the environment. For example, Figure 2 shows a user's profile page and Figure 3 shows a user's personal dashboard in the Elgg configuration used for this study. Once logged on, students first encountered their dashboards, which they were able to edit by adding or removing features.

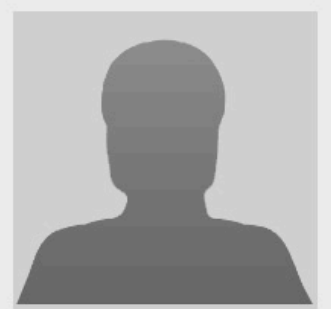

John Doe

Glad to be back, everyone!

(4 minutes ago)

Location: my city

Interests: cycling, reading, cooking

Skills: design \& development of corporate training

Contact email: sample-student@email.edu

Telephone: XXX-XXX-XXXX

Website: http://www.mywebsite.org

Friends

Friends of

About me

I am enrolled in the Educational Technology program at ABC university. This is my first online course and I am excited, but also a bit nervous. This topic is closely related to my job, and I am very interested in learning more about it. This summer, I am looking forward to enjoying a two-week Caribbean cruise with my parents and children.
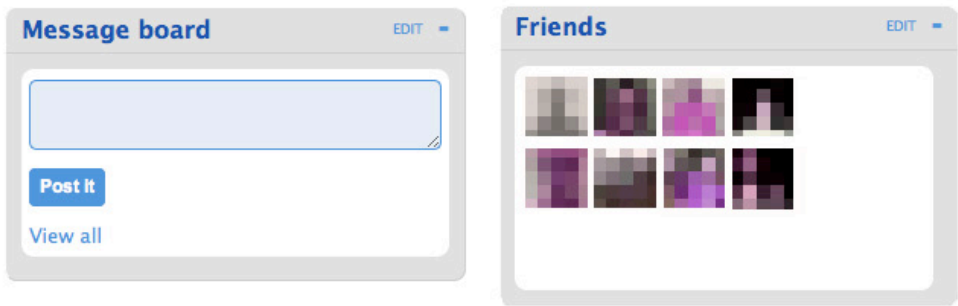

Edit page

Blog
$\begin{aligned} & \text { Blog: Reflecting on my digital } \\ & \text { footprints } \\ & \text { John Doe } 3 \text { minutes ago }\end{aligned}$
More blog posts

Wire posts

John Doe: Glad to be back, everyone!

Posted to the wire 4 minutes ago via Site.

More wire posts

\section{Bookmarks}

EDIT -

New York Times: Rise in Online Classes Flares Debate About Quality John Doe just now More

More bookmarks

Figure 2. Student profile. 

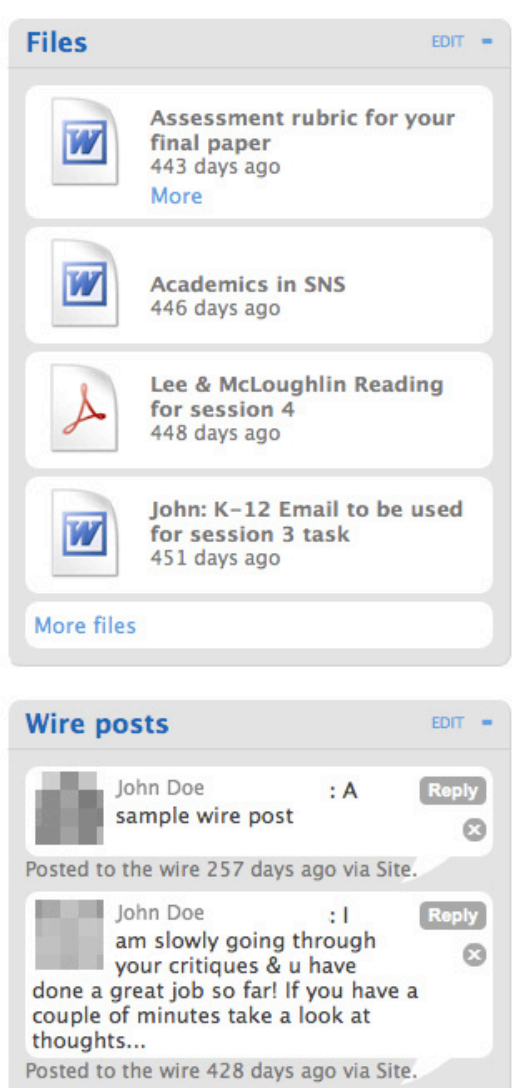
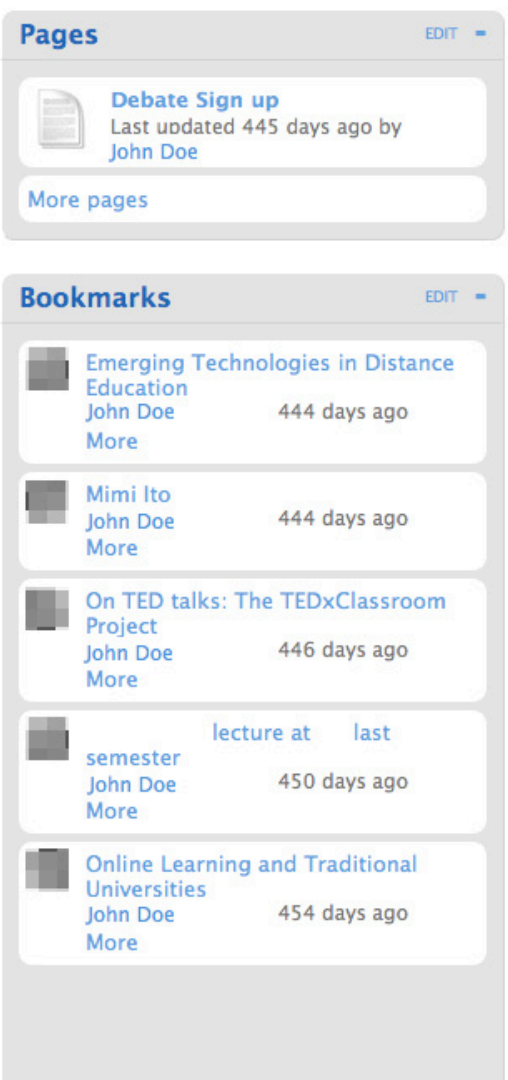
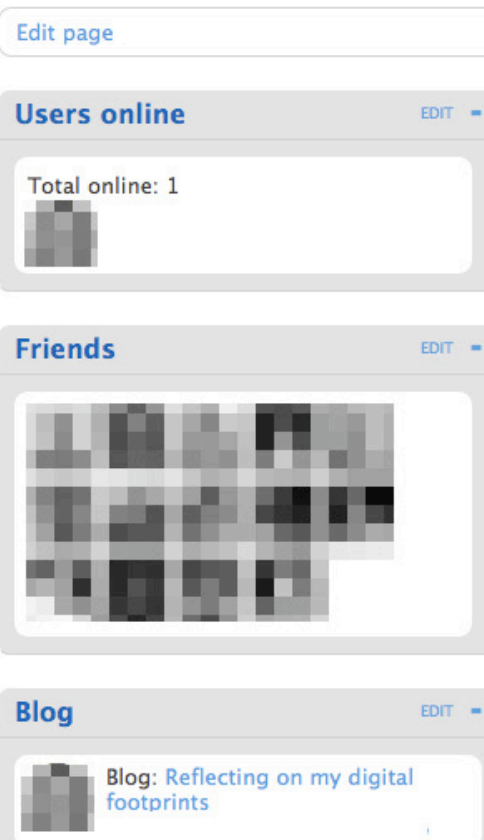

Blog: Final paper and questions

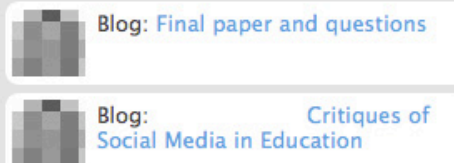

Figure 3. The original configuration of the student dashboard.

While users were able to follow other students' activities on their dashboards, they were also able to visit affordance-specific pages in order to access updates pertaining to a specific activity. For example, Figure 4 shows the page that users were able to visit in order to view everyone's bookmarks. 


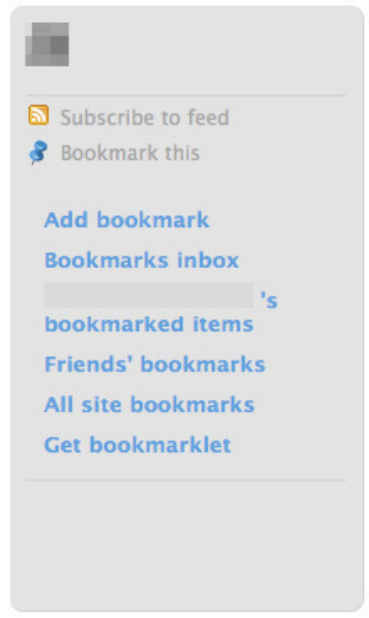

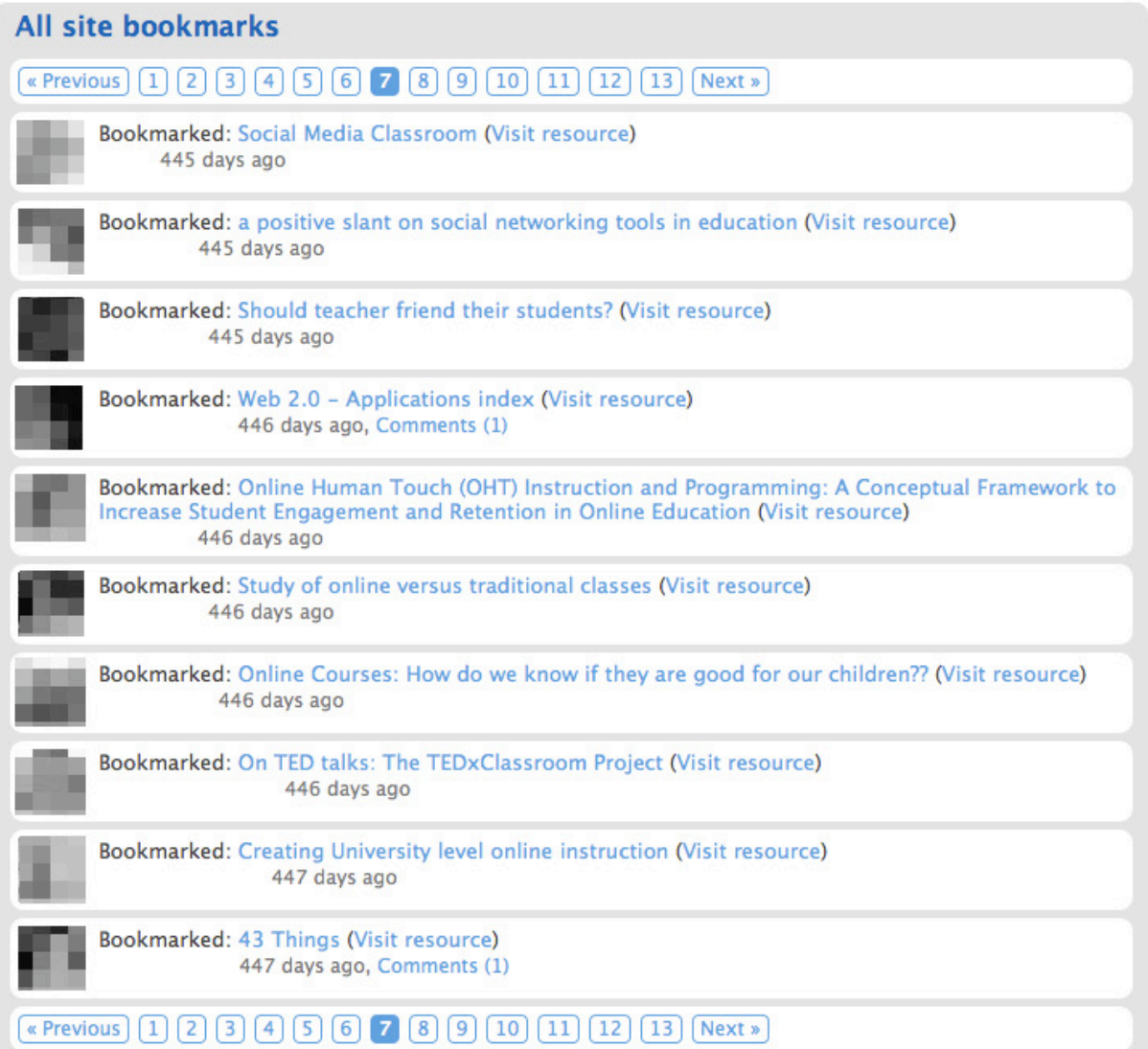

Figure 4. User bookmarks page.

We thought Elgg was uniquely positioned to function as an online social network for hosting formal educational endeavors. In addition to offering a few pragmatic affordances that appealed to us (e.g., access to a diverse array of social tools such as bookmarking, microblogging, and blogging within one location), the platform also seemed to align quite well with a socioconstructive ethos of learning. Rather than viewing learning as acquisition of a body of knowledge, we perceived it as consisting of participation within the sociocultural environment that we created. This perspective is informed by the works of Vygotsky (1962, 1978) and Lave and Wenger (1991). Social constructivism contends that learning is a social process supported through interaction, dialogue, sharing personal experiences, peer/ instructor support and scaffolding, and personal and social meaning-making. We saw Elgg as supporting and complementing socioconstructivism as the environment seemed to (a) respect participants' voices without centering on or elevating the instructor, and (b) enable individuals to have access to varied information streams in the same way that these exist in popular social networking tools.

\section{Method}

\section{Participants}

Ten out of 14 learners enrolled in this course agreed to participate in the study. Nine par- 
ticipants reported their gender ( 6 female, 3 male), and all reported their age ( $M$ 37, $S D$ 9.2) and the degree they were pursuing (five $\mathrm{PhD} / \mathrm{EdD}$ and five MA/MS). One student had received her undergraduate degree online, four students had never taken an online course, and the rest had taken three or fewer online courses. Three participants pursued a degree in educational technology, and the rest pursued a degree in other education-related specialties. All participants reported having a computer at home and were comfortable with using the Internet for learning purposes. For instance, all of them either agreed or strongly agreed with the statement, "I am able to use the Internet for personal learning," and nine out of ten completely agreed or agreed with the prompt "Using the Internet to learn about a topic that interests me on my own excites me." Nine out of ten also disagreed or strongly disagreed with the prompt "Using the Internet to learn about a topic that interests me on my own stresses me out." With regards to using social software in their personal life, eight participants reported having a Facebook account (six used it on a daily basis), three reported having uploaded a video on a video-sharing site in the past, and six reported having uploaded photos on a photo-sharing site in the past.

\section{Data Sources}

The data corpus was collected within one to two weeks after the end of the course and consisted of personal interviews (dominant data source) and survey responses (secondary data source). The interviews lasted between 45 minutes and one hour each. Both of us conducted the first interview, and the author who was not the course instructor conducted all subsequent interviews in order to reduce the possibility of respondent bias. The interviews consisted of a set of open-ended questions, and follow-up questions were used to solicit further information. Interviews were audio-recorded and transcribed verbatim. The survey was primarily used to collect demographic and educational information, and prior experiences with technology, social media, and online education. The survey also included open-ended questions that sought feedback about (a) student experiences, and (b) specific activities and attributes of the course.

\section{Data Analysis}

Methodologically, this study falls within the broad framework of the interpretive research paradigm. Under the interpretive research paradigm we employed a case study method (Yin, 2003), where the Elgg-using classroom was perceived to be the case under investigation. We used the constant comparative method (Glaser \& Strauss, 1967) to analyze interviews and survey responses, arriving at salient categories and data patterns. Both of us engaged in open coding of all the data, independently reading and analyzing it to note emerging patterns with regards to students' experiences in the online course. We then met six times to discuss identified categories, compare notes, and collaboratively analyze data in search of common themes and meanings. The patterns we discovered were compiled and reanalyzed in order to confirm and disconfirm the codes across participants. Open coding of the data resulted in 26 codes relevant to the research questions. We continued the analysis until we could not identify any new themes or coding categories and felt that the data had been completely represented by the final codes/themes (i.e., the data had been saturated). Once patterns were identified, we grouped them into themes. 


\section{Validity and Reliability}

Several triangulation methods were used to enhance the study's validity and reliability. First, we collected data from multiple sources (survey and interviews). Second, we analyzed each data source independent of other data sources. Third, we each analyzed the data independently and then met to discuss our findings. These methods enabled us to (a) examine the accuracy of the collected data, and (b) reduce the possibility of researcher bias in drawing conclusions from the data. A potential threat to the study's validity and reliability is that participants may have (consciously or unconsciously) reported on issues they believed to be valuable to the instructor due to his dual role as instructor and researcher. We sought to minimize this threat by repeatedly encouraging participants to report their perspectives as opposed to what they believed the instructor wanted to learn about.

\section{Results}

The identified themes focus on the social attributes of the online learning experience, student perceptions of the social networking platform, and student management of learningrelated processes.

\section{Social Attributes of the Student Experience}

The dominant theme that arose from the interviews concerned the social nature of the learning experience. Social interaction, combined with meaningful knowledge building, was a significant element in the course.

Interaction, communication, and social connectivity.

All students interviewed and nine out of ten students surveyed stated that they found great value in their interactions with other students and the social setting in which the course was set. When asked to reflect about their course experiences, students predominantly focused on describing their connections and interactions with others, and the value they found in peer collaboration and support. For example, Bob ${ }^{1}$ said that the social nature of the course was "as intellectually engaging as I have been involved in a while," and Joan, comparing the course to a previous learning experience, expressed a similar view, "this time ... I did the assignment but there was a whole lot more interaction afterwards and I really appreciated that." Mary also compared the experience to traditional face-to-face courses that she has taken and noted that she "really lik[ed] that connection with our classmates, it's interesting that in a traditional face-to-face course, I don't always feel as connected to my classmates, even though I'm going to be sitting right next to them, engaged in face-to-face conversation."

Learners also found their interactions with others were important in helping them make sense of the subject matter and reported that these interactions extended their learning.

$1 \quad$ All names are pseudonyms. 
Jen commented,

Some of the questions they [other students] would post made me have to think about it ... further than the paper ... and reading some of their posts, I would realize, 'Oh, I didn't think of it that way.'

According to Bob, participants' diverse experiences meant that each person had something valuable to contribute, and Nancy explained that such contributions had an impact on her: "Gary had ... a lot of experience ... and his experiences and his thoughts and his reflections really inspired me."

The ease with which participants were able to communicate was also deemed to be important to social connectivity. For example, participants pointed out the following valuable affordances: the ability to navigate efficiently through the social network, to easily reach student and instructor blogs, to effortlessly access course content, and to be notified of comments to their blogs via email. Referring to the platform, Cindy observed that she liked "having access to all the things that everyone posted," and Lucy noted that this allowed her to "ask questions more easily and ... communicate ... thoughts and ideas more easily." Significantly, Mary clarified that ongoing dialogue between students was important because simply responding to questions is "like you're just in it as a clock in, clock out kind of thing, and that's not really the realm of education."

\section{Social presence and identity.}

At the beginning of the course, students were asked to create a profile on the social networking site; share a photograph of themselves; post information on their majors and interests both in and outside of class; share summer plans that they were looking forward to; and view one another's profiles. This activity was an attempt to introduce students to one another and to the instructor, to explore common interests, and to establish social presence. Social presence has been defined by Garrison, Anderson, and Archer (2000, p. 89) as participants' ability "to project their personal characteristics into the community, thereby presenting themselves to other participants as 'real people." Students in this study discussed finding value in viewing other learners' profiles, but they also expressed concerns with regards to appropriately representing themselves online and correctly understanding other students' actions.

Bob commented that other students' profiles and interests gave him "a greater sense of connection to the course, also to my colleagues that were online," while Betty noted that the online profiles and course discussions "made me feel, oh wow, they're real people, they're not just these little icons on the screen." The connections that students formed allowed Don to contribute more to the course, as he commented,

I find that when I have ... a sense that this is ownership, within the site ... I tend to put ... more into it ... writing 
the assignment, expressing myself, clarifying my thoughts

and so on.

Other students described positive experiences they had with specific individuals. For instance, Nancy, a student from Germany, described sharing a personal story, and stated "the reason that I could have confidence to share my story was Betty ... she has German friends, she knows [the] German language too, and . . . that lowered my anxiety." Lucy reported enjoying her interactions with Gary, "who always had the coolest posts. I loved what he had to say." As the students progressed through the course, they were able to share personal experiences and identify with others as a result.

Nevertheless, negotiating their presence in the environment was also a point of tension, and about half of the students expressed concerns either with how they presented themselves or how others perceived them online. On the one hand, Betty discussed trying to find an appropriate voice with which to participate in the course. As she stated, "I'm blogging for a class, so I have to be more formal ... I don't see my voice coming out." On the other hand, both Don and Cindy struggled with creating representative portrayals of their colleagues. Don, for instance, asked "how many of those canned introductions give you an understanding of who this individual is, or what kind of experiences they've had? What kind of wealth of knowledge are they bringing to the conversation?" Cindy's experiences capture the complexities of this issue because even though she stated that "student-student interactions within this course were much better than any of the other online and hybrid courses I've taken" she still felt that "the comments on my blog posts by some students were either contrived to fulfill a grading requirement or outright argumentative." She clarifies this issue by noting that "my opinion is tentative on this issue because it was difficult to understand the [other students'] intentions for responding to my blog posts."

\section{Pedagogical considerations.}

Learners also alluded to the student-centered pedagogy used by the instructor as a positive contributor to the learning experience. Betty noted that she "realized it was just about good teaching ... following or putting together a really good curriculum for the students and just making the most of all the tools and using them as tools to support instruction." Another student stated that

The blogs were great. Just the whole back and forth that [the instructor] had us do where we actually posted [blog entries] and then we had to respond to someone else's, and then respond to everyone else that was responding to us ... the [instructor] really challenged us ... I really started getting more out of it.

Joan had similar thoughts, relating that she liked the conversations with others, especially when people disagree with me or have different 
viewpoints because I would have to look at their viewpoint and then see which one was actually working ... I think that's what education should be about, about making people ... consider other people's opinions.

Finally, in a moment of reflection, Lucy noted that the pedagogical approach not only helped her learn the content but also improved her own teaching practices:

I feel that I learned a great deal . . . the readings and from what everyone had to say, I feel like I just kind of internalized it all. ... I've been working very closely with our technology teachers ... on different things we can do for our students that are in the middle school where I work, so I thought it was a great experience.

\section{Online Learning Mediated by a Social Networking Site}

This theme describes students' initial apprehensions with online courses in general and their subsequent excitement about the opportunities afforded by this specific online course; students' comparisons between the Elgg SNS and other platforms they used; usability problems, barriers to learning, and recommendations for enhancing the Elgg platform.

\section{From apprehension to positive learning experiences.}

Four students, all new to online courses, described the apprehension that they experienced at the start of the course. These students were concerned they would lose intimacy and discipline by being in an online course. Gary explained,

it was my first online class, I really didn't know what to expect, ... . so I was a little apprehensive, I wasn't sure if . . . my personality would fit in, I'm something of a procrastinator, so I was afraid that somehow I'd lose the discipline of a face-to-face classroom time and end up falling behind.

Mary shared similar feelings, reporting "at first, I was a little overwhelmed ... I really didn't know what was expected," and Betty found that "especially the first couple of assignments, I felt like I was completely lost." Nevertheless, all four learners reported that these initial apprehensions were resolved once they became acquainted with the online environment and accustomed to the daily requirements, structured pace, and consistent rhythm of the course. Appreciation for the opportunities afforded by the collaborative nature of the online course quickly replaced learners' initial apprehensions. Cindy reported that the experience, "was very collaborative ... everybody was in there together and that's another really good aspect of the online environment ... there's not that one person in charge, standing at the front of the class." Additionally, Betty noted that she enjoyed the flexibility, describing herself as "a homebody" who "likes doing things on [her] own time," while Don observed that 
the online course allowed participation from geographically scattered participants:

[What] I enjoyed about this course was that there were people with diverse background[s]. For example, Bob apparently is some kind of administrator in college ... we had a student in Puerto Rico, and she wouldn't have been able to join ... we had a student, I think, in Syria.

Survey responses indicated that by the end of the course, seven participants completely agreed and three agreed with the prompt "After taking this course, I feel comfortable with the idea of taking an online course."

\section{Comparison to other platforms.}

Learners also reflected on past learning experiences and compared the social networking platform to others they experienced (most frequently this was Blackboard because it was used institution-wide). More specifically, students expressed a preference for the social networking platform over other traditional course management systems, as reflected by Don's comment, "I appreciated using Elgg over, say, using Blackboard or another CMS that I have had to use in other courses." Mary and Nancy also expressed a preference for the social network over other platforms. Mary noted that she "thought it was excellent ... we have other learning management systems. . . . But I thought it had everything right where we wanted it." Nancy identified the social interface on the SNS as superior to a variety of other platforms:

I used Blackboard, CollegeLMS ${ }^{2}$, and Moodle and Ning . .

. to me, Elgg was the newest and the most fresh thing, to me, I really liked the interface, it's kind of friendly ... For example ... I really feel formal with Blackboard ... [like] I'm facing the professor.

Gary summarized such feelings when he stated that "embedding those features, photos, links, all that, I think, contributed to learning ... in contrast to [other LMSs] where it's even more difficult to do that." The extent to which such positive perceptions are the result of the social network, however, is debatable because pedagogy and technology were inextricably intertwined, and Elgg, in this case, cannot be regarded to be independent of the pedagogy with which it was used. We will return to this point in the discussion section of the paper.

\section{Technological barriers to learning.}

Despite the positive experiences, students identified particular features of the platform as problematic in terms of usability and inhibitive to their learning experience. These barriers were the result of missing functionality that detracted from efficient and effective commu-

2 CollegeLMS is a pseudonym for the LMS designed for and used by the College of Education at the institution where this study took place. 
nication and collaboration. For instance, Don and Gary both felt a more intuitive navigation system would have been more usable. Don said that he "felt that I had to click on each person's blog post ... to read comments to the blogs, to understand what kind of conversation was happening there," while Gary suggested that "it would be nice if somehow it had a feature that would let me sort of scan all the comments instead of having to go to each person's blog individually." Lucy also asked for a better blog management structure because she found that newer blog entries suppressed older ones: "I was late on an assignment because [the instructor's] blog post got buried and I didn't see that, so that was one thing that kind of threw me off toward the end of the class." One issue that bothered all the students was Elgg's inability to inform them of responses to comments they had left on other students' blogs. For example, when students commented on Gary's blog, he received an email notification about this activity. When Gary responded to these comments, however, the students did not get a notification that he had taken this action. They wouldn't necessarily know that Gary had replied to their comments without coming back to his blog to check for responses. This problem frustrated students, contributed to time demands, and made continuous interaction difficult. One way of resolving this issue is to provide students with the option to be notified of follow-up comments on a blog entry they respond to, or, as Lucy suggests, "it would be neat to have a feature where your name was tagged or ... anytime you'd mention someone's name they are notified."

\section{Managing Information and Participation}

Learners also discussed information management and network participation as it pertained to their learning and interactions with one another, noting that they felt a need to formulate methods and strategies for dealing with time constraints and the perceived abundance of ideas and resources that were available in the course.

As the students worked through the assigned readings and activities, managing and organizing information proved to be a challenge. Betty stated that,

reading all of my classmates blogs and comments, commenting on the blogs and/or comments, reading the material for the course, trying to find and read any supplementary material, and then composing a blog is taking significantly more [time than] the course is supposed to take. I am taking two other courses, and I find that I do not have enough time to devote to all of my classes.

Numerous other students shared this feeling. Our interviews revealed that students either used technology tools to manage what they perceived to be "abundance of information," or devised personal strategies for information management. Elgg provided one such feature to manage information and participation, and one student stated,

I enjoyed that the system sent email notifications regarding the items submitted to the site . . . having 
notifications helped me manage my time better by not having to consistently remember to log into the site to find out what has been added.

Personal strategies for managing information focused on time-saving techniques. For example, Cindy would sort through the blogs to respond to the ones that dealt with topics that interested her. Taking a different track, Nancy responded primarily to individuals who had written informative and insightful entries in the past, while both Cindy and Mary described reading and scanning blog entries for relevance. For instance, Cindy stated that she "might read a little piece of this and little piece of that or skip all the way to the bottom." Bob's "workaround" for deciding on whom to interact with focused on ensuring communicating with individuals who had a different opinion: "I found that I would go to the people that either had a similar take to my own and [who I] agree with; probably more often, people [who] had a different take on it." Gary's workaround indicated that he, too, had certain individuals he preferred to interact with:

I tried to make sure I went and read at least everybody's comments, at least once during the class, um, but there were clearly certain individuals that I would go back to more often and read what they had to say.

It appears that learners' strategies for managing their time often centered around scanning or skimming other students' contributions and making selections based on their best judgment for the appropriate circumstance. Betty, for example, described feeling overwhelmed when she searched the Web to find and share pertinent information as part of the social bookmarking activity. "I wish I had more time ... [you] start finding other things and there's so much information, and there's no way to get a tiny fraction of all the information out there." She described her method of time management in this way: "I had to consciously tell myself, okay, you've been doing this for twenty minutes, stop now; go do your work for your other class." As Nancy elaborated about her time-saving strategies, "I didn't read every reflection, I had some preferences." Lucy and Mary both noted that they also had commitments outside of class and therefore had to make choices about the extent to which they engaged with course activities and their day-to-day life. For example, Mary noted,

my schedule at home is busy, so it was a matter of just getting the readings done and thinking about them and working on the posts, and so there wasn't any time in between ... for back and forth discussion, because it was just a time frame ... so I didn't have time for all of that.

\section{Discussion}

Findings from this study indicate that learners enjoyed and appreciated the social learning experience afforded by the combination of the online social network and the employed 
pedagogy. Learners supported one another in their learning and noted that they perceived their learning experience was enhanced by their interactions. Nevertheless, in contrast to claims from the existing literature on informal learning in SNSs, and in support of emerging empirical evidence from the use of online social networks in hybrid courses (Arnold \& Paulus, 2010), learners limited their public activity to course-related topics. Additionally, students did not appear to mix social and educational participation and seemed to need support in managing the expanded amount of information available to them. In order to manage their time and participation, learners devised strategies and "workarounds" to complete assigned activities and course commitments.

In this study, we found evidence that the focus of the course was on the learner and his or her interaction with his or her peers. Frequent and ongoing participation and collaboration within the context of the social network (in combination with the relatively short duration of the course) seemed to mitigate the problems traditionally facing online learners, such as isolation and lack of support, while contributing to a positive learning experience. It is unclear, however, whether the problems traditionally facing distance learners were addressed as a result of introducing the social networking platform, as a result of the instructor's pedagogical approach, or as a result of the platform offering affordances that enabled social pedagogies to be implemented. Even though prior literature has recognized that the relationship between pedagogy and technology is complex and negotiated (Veletsianos, 2010), this is further evidence of the tensions that exist between the two. While the educational technology literature indicates that technology alone does little to improve educational outcomes (e.g., Clark, 1983), we also suggest that researchers and educators should resist allowing pedagogy and familiar instructional approaches to determine how technologies are used in online learning settings. Steps that can help instructors to move in this direction are using technology as a "means to provide opportunities for personally relevant and meaningful transformation" (Veletsianos, 2011) and working to eliminate the obstacles (e.g., Internet filtering, mandated technology policies) that structure how educational technology is used and constrain its use within familiar molds.

While this study indicates that networked learning opportunities are promising and that learners cherished the opportunities for interaction presented to them, information and participation management was one of the tensions that arose in this course. On the one hand, the learners' act of devising strategies and "workarounds" to complete the activities assigned to them indicates that some were reflective, self-directed, and able to individually figure out ways to solve the problems they were facing. Nevertheless, this finding introduces two other issues:

- Some learners lacked this ability. Unfamiliarity with ways to manage their own learning points to a need for teaching network learning skills, such as the ability to find and categorize content for future retrieval and traverse networks of interest (Jenkins et al., 2006). Such skills are also transferable to learners' lives outside of formal education as they enable individuals to utilize online social networks to manage and further their lifelong learning. 
- Workarounds, while effective at enabling learners to successfully complete course requirements, can also be seen as activities that potentially undermine their exposure to diverse opinions that collaborative learning activities seek to attain. This may not be true of all workarounds (e.g., Bob sought individuals who expressed opinions that differed from his), but the risk is that information abundance, coupled with an inability to manage information, may create echo chambers in which like-minded individuals interact with one other, isolating themselves from diverse or differing opinions (Sunstein, 2002). One way to target this issue is to ask, what do the workarounds tell us about improving future courses? In response, one idea is to structure activities in such a way that students are asked to take sides and argue for opinions that they do not espouse (e.g., online debates). A second idea is to develop technological solutions. For instance, the platform could track student interactions and indicate to learners their participation patterns, alerting them when their activity (e.g., interaction with one other member) is isolating them from the group, or when textual analysis of their contribution suggests high levels of agreement with the individuals with whom they interact.

Prior research has indicated that participants in social networking sites embrace the opportunity to demonstrate various dimensions of their personality by posting images and videos that are meaningful to them (Greenhow \& Robelia, 2009). However, in this study we found minimal evidence of learner activities beyond what they were instructed to do. Learners shared information about themselves either because the instructor asked them to (e.g., they had to create a personal profile) or because it served to clarify the arguments they presented in their blog entries. One student even commented specifically to this, saying she "was disappointed that very few (only one person) responded or seemed to look at information [that she posted] that was related to the course, but not part of the assigned comments." Therefore, even though learners contributed their personal experiences and examples when answering questions or responding to one another, they did not appear to mix social and "educational" life. Indeed, the pace of the course was fast, which may have resulted in limited student control and time to explore the site's social features. Nevertheless, this is especially interesting given that numerous students alluded to the social experience they had in this course. It appears that while the technology and pedagogy enabled (and even encouraged) sharing, students used the online learning environment in a strict educational (albeit socially enhanced) manner, deviating little from the tasks and assignments, and focusing on the activities that were graded. While this observation should not be surprising, it stands in contrast to the techno-centric and pedagogy-centric perspectives often embraced within the educational technology field and highlights the need for further study of the "often compromised and constrained social realities of technology use "on the ground” (Selwyn 2010, pp. 66). Elgg is a framework and, as such, it can become many things. Though it includes social networking features as part of its design, these were not the features used in the course. This is reminiscent of what Dron and Anderson (2009b) have called "Web 1.5," the construction of environments that lie in between the two extremes of teacher-centric LMSs and generic social software tools. Environments such as the one described here may include the sharing and read/write capabilities found on the social Web, but they are constrained by the setting in which they occur. Under such circumstances 
it would be highly unlikely for social networking to occur. To figure out how to encourage social networking within the context of formal education, one has to investigate the entire system's impediments more closely and examine not just technological and pedagogical alignment but broader contextual influences such as institutional constraints and cultures (e.g., in this study, the fast pace of the summer course may have reduced learner control, impeding the learners' abilities and motivations to explore the social tools). To reach this goal, it may be worthwhile to consider social networking as a feature rather than a destination (Anderson, 2007). Rather than viewing online social networks as locations that students visit to interact with one another, it may be more productive to evaluate which social networking features are valuable in day-to-day educational experiences, how such features are compatible with academic cultures and values, and how such features are used in realworld interventions.

\section{Conclusion}

Online learning in higher education in the US is on the rise. At the same time, social networking sites have gained wide societal interest. In this study, a social networking platform was used as a medium to teach a graduate-level online course. The study is deliberately tied to its context so as to offer a rich and holistic picture of the interactions between technologies, pedagogies, and educational setting. Results indicate the complexities of implementing social networking technologies in ecologically valid environments, highlighting the benefits and multifaceted tensions that may result when adopting such tools in online education. While this research focuses on one case with a small sample size, it offers insights and explanations that go beyond its immediate setting, corroborating emerging evidence from other case studies. These results indicate that learners (a) did not engage with one another in activities beyond what was required for course credit, (b) needed support to navigate the online social network, and (c) devised personal strategies to manage participation and online presence. Future research on the topic might delineate the reasons for and impacts of student workarounds and examine cases in which learners exhibit greater social presence on online social networks so that we can better understand this phenomenon. Finally, future research could also investigate the voice of the instructor when teaching on online social networks, which is a voice that is missing from both this paper and the relevant literature.

\section{Acknowledgments}

The authors would like to thank two anonymous reviewers for their feedback and suggestions. 


\section{References}

Ajjan, H., \& Hartshorne, R. (2008). Investigating faculty decisions to adopt Web 2.0 technologies: Theory and empirical tests. The Internet and Higher Education, 11(2), 71-80.

Allen, E., \& Seaman, J. (2010). Learning on demand. Online education in the United States, 2009. Needham: Sloan Center for Online Education. Retrieved from http://www. sloan-c.org/publications/survey/pdf/learningondemand.pdf

Anderson, C. (2007). Social networking is a feature, not a destination. [Web blog post]. Retrieved from http://www.thelongtail.com/the_long_tail/2007/o9/social-networki.html

Arnold, N., \& Paulus, T. (2010). Using a social networking site for experiential learning: Appropriating, lurking, modeling and community building. The Internet and Higher Education, 11(2), 71-80.

Barbour, M., \& Plough, C. (2009). Social networking in cyberschooling: Helping to make online learning less isolating. TechTrends, 53(4), 56-60.

Brady, K. P., Holcomb, L. B., \& Smith, B. V. (2010). The use of alternative social networking sites in higher educational settings: A case study of the e-Learning benefits of Ning in education. Journal of Interactive Online Learning, 9(2), 151-170.

Clark, R. E. (1983). Reconsidering research on learning from media. Review of Educational Research, 53(4), 445-459.

Conole, G. (2010). Facilitating new forms of discourse for learning and teaching: Harnessing the power of Web 2.o practices. Open Learning, 25(2), 141-151.

DeSchryver, M., Mishra, P., Koehleer, M., \& Francis, A. (2009). Moodle vs. Facebook: Does using Facebook for discussions in an online course enhance perceived social presence and student interaction? In I. Gibson et al. (Eds.), Proceedings of Society for Information Technology \& Teacher Education International Conference (pp. 329-336). Chesapeake, VA: AACE.

Doering, A., \& Veletsianos, G. (2008). Hybrid online education: Identifying integration models using adventure learning. Journal of Research on Technology in Education, 41(1), 101-119.

Dron, J., \& Anderson, T. (2009a). How the crowd can teach. In S. Hatzipanagos \& S. Warburton (Eds.), Handbook of research on social software and developing community ontologies (pp. 1-17). Hershey, PA: IGI Global Information Science.

Dron, J., \& Anderson, T. (2009b). Lost in social space: Information retrieval issues in Web 1.5. Journal of Digital Information, 1O(2), 1-12. 
Galusha, J. M. (1997). Barriers to learning in distance education. Interpersonal Computing \& Technology, 5(3-4), 6-14.

Garrison, R., Anderson, T., \& Archer, W. (2000). Critical inquiry in a text-based environment: Computer conferencing in higher education. The Internet and Higher Education, 2(2-3), 87-105.

Glaser, B. G., \& Strauss, A. L. (1967). The discovery of grounded theory. Chicago: Aldine Publishing.

Greenhow, C. (2011). Online social networking and learning. International Journal of Cyber Behavior, Psychology and Learning, 1(1), 36-50.

Greenhow, C., \& Robelia, B. (2009). Old communication, new literacies: Social network sites as social learning resources. Journal of Computer-mediated Communication, 14(4), 1130-1161.

Greenhow, C. G., Robelia, B., \& Hughes, J. (2009). Learning, teaching, and scholarship in a digital age Web 2.0 and classroom research: What path should we take now? Educational Researcher, 38(4), 246-259.

Hughes, J., Thomas, R., \& Scharber, C. (2006). Assessing technology integration: The RAT - Replacement, Amplification, and Transformation - framework. In C. Crawford et al. (Eds.), Proceedings of Society for Information Technology \& Teacher Education International Conference (pp. 1616-1620). Chesapeake, VA: AACE.

Jenkins, H., Clinton, K., Purushotma, R., Robinson, A. J., \& Weigel, M. (2006). Confronting the challenges of participatory culture: Media education for the 21st century. MacArthur Foundation. Retrieved from http://www.digitallearning.macfound. org/

Lane, L. (2009). Insidious pedagogy: How course management systems impact teaching. First Monday, 14(10).

Lave J. \& Wenger E. (1991) Situated learning: Legitimate peripheral participation. Cambridge University Press, Cambridge, UK.

Lee, M. J. W., \& McLoughlin, C. (2010). Beyond distance and time constraints: Applying social networking tools and Web 2.o approaches to distance learning. In G. Veletsianos (Ed.), Emerging technologies in distance education (pp. 61-87). Edmonton, AB: Athabasca University Press.

Madge, C., Meek, J., Wellens, J., \& Hooley, T. (2009). Facebook, social integration and informal learning at university: 'It is more for socialising and talking to friends about work than for actually doing work.' Learning, Media and Technology, 34(2), 141. 
Mishra, P., \& Koehler, M. (2006). Technological pedagogical content knowledge: A framework for teacher knowledge. Teachers College Record, 108(6), 1017-1054.

Naveh, G., Tubin, D., \& Pliskin, N. (2010). Student LMS use and satisfaction in academic institutions: The organizational perspective. The Internet and Higher Education, 13(3), 127-133.

Peters, O. (1992). Some observations on dropping out in distance education. Distance Education, 13(2), 234-269.

Schroeder, A., Minocha, S., \& Schneider, C. (2010). The strengths, weaknesses, opportunities and threats of using social software in higher and further education teaching and learning. Journal of Computer Assisted Learning, 26(3), 159-174.

Selwyn, N. (2009). Faceworking: Exploring students education-related use of Facebook. Learning, Media and Technology, 34(2), 157-174.

Selwyn, N. (2010). Looking beyond learning: notes towards the critical study of educational technology. Journal of Computer Assisted Learning, 26(1), 65-73.

Sunstein, C. (2002). Republic.com. Princeton, NJ: Princeton University Press.

Tallent-Runnels, M. K., Thomas, J. A., Lan, W. Y., Cooper, S., Ahern, T. C., Shaw, S. M., \& $\mathrm{Liu}, \mathrm{X}$. (2006). Teaching courses online: A review of the research. Review of Educational Research, 76(1), 93-135.

Veletsianos, G. (in press). Higher education scholars' participation and practices on Twitter. Journal of Computer Assisted Learning.

Veletsianos, G. (2011). Designing opportunities for transformation with emerging technologies. Educational Technology, 51(2), 41-46.

Veletsianos, G. (2010). A definition of emerging technologies for education. In G. Veletsianos (Ed.), Emerging technologies in distance education (pp. 3-22). Edmonton, AB: Athabasca University Press.

Vygotsky, L. S. (1962). Thought and language. Cambridge, MA: MIT Press.

Vygotsky, L. S. (1978). Mind in society. Cambridge, MA: Harvard University Press.

Wang, Q. Y., Woo, H. L., Quek, C. L., Yang, Y. Q., \& Liu, M. (in press). Using the Facebook group as a learning management system: An exploratory study. British Journal of Educational Technology.

Webb, E. (2009). Engaging students with engaging tools. Educause Quarterly, 32(4), 1-7.

West, R., Waddoups, G., \& Graham, C. (2006). Understanding the experiences of instruc- 
tors as they adopt a course management system. Educational Technology Research and Development, 55(1), 1-26.

Wheeler, S., Yeomans, P., \& Wheeler, D. (2008). The good, the bad and the wiki: Evaluating student-generated content for collaborative learning. British Journal of Educational Technology, 39(6), 987-995.

Whitworth, A., \& Benson, A. (2010). Learning, design, and emergence: Two cases of Moodle in distance education. In G. Veletsianos (Ed.), Emerging technologies in distance education (pp. 195-213). Edmonton, AB: Athabasca University Press.

Yin, R. (2003). Case study research: Design and methods (3rd ed.). Thousand Oaks, CA: Sage.

\section{Athabasca University $\mathbf{A}$}

(c) 